\title{
STUDIES OF THE SUBSTITUTION EFFECTS ON THE ELECTRONIC PROPERTIES FOR BIPHENYL AND DERIVATIVE MOLECULES BY USING DFT METHOD
}

\author{
Rajaa Khedir Al-Yasari \\ University of Karbala, College of Science, Physics Department, Karbala, Iraq \\ e-mail:ralyasarair@gmail.com
}

\begin{abstract}
DFT method has been carried out to study the substitution effects of $\mathrm{NO}_{2}$ group on the electronic properties (ionization potential, electron affinity, electronegativity, hardness, softness and electrophilicity index) and IR spectral properties of biphenyl and derivative molecules by using the B3LYP functional and the $3-21 \mathrm{G}$ basis set, as well as the optimization structure. The calculated values of HOMO and LUMO energies, as well as predicted by ChemBioDraw program ${ }^{1} \mathrm{H}$ and ${ }^{13} \mathrm{C}$ NMR spectra for the studied compounds are in a good agreement with experimental data. All properties were calculated by using Gaussian 09 program and GaussianView 5.08 program, except NMR characteristics.
\end{abstract}

Keywords: DFT calculation, electronic properties, IR and NMR spectra, biphenyl molecule.

Received: September 2015/ Revised final: January 2016/ Accepted: January 2016

\section{Introduction}

Biphenyl is an aromatic hydrocarbon with a molecular formula $\left(\mathrm{C}_{12} \mathrm{H}_{10}\right)$, which is an organic compound that forms colorless crystals. It consists of two connected phenyl rings and has $\mathrm{D}_{2}$ symmetry [1]. Biphenyl has density $1.04 \mathrm{~g} / \mathrm{cm}^{3}$, melting point $69.71^{\circ} \mathrm{C}$ and boiling point $255^{\circ} \mathrm{C}$ [2], being used in organic syntheses, food preservatives, heat transfer fluids and as an intermediate for polychlorinated biphenyls [3]. The biphenyl derivatives, such as polychlorinated biphenyls (PCB), were widely used as dielectric and coolant fluids in electrical apparatus, cutting fluids for machining operations and carbonless copy paper. 4-Aminobiphenyl has been used formerly as a rubber antioxidant and it is still used in the detection of sulfates and as a model carcinogen in mutagenicity studies and cancer research [4,5]. Many studies have been carried out on the theoretical calculations of electronic structure, ionization energy and IR spectra for azide group in $3^{\prime}$-azido-3'-deoxythymidine (AZT), compared to small azide compounds by the using DFT method and $\mathrm{B} 3 \mathrm{LYP} / 6-311 \mathrm{G}^{* *}$ basis set [6].

Geometry optimization has been performed and the electronic structure, total energy, electronic potential surface, UV and IR spectra were computed using TD-DFT//B3LYP method with 6-311G $(\mathrm{d}, \mathrm{p})$ basis sets for isoniazid and its derivative N-cyclopentylidenepyridine-4-carbohydrazide molecules [7]. The correlation between the crystalline structure and vibrational modes of the latter has been discussed [7]. Theoretical study of calculating the molecular structure and electronic properties of diphenylanthrazolines molecule was performed using density functional theory with B3LYP/6-31 G* level [8]. Finally, a study has been carried out to highlight the substitution effects of $\mathrm{H}, \mathrm{NH}_{2}, \mathrm{NMe}_{2}$, $\mathrm{OCH}_{3}, \mathrm{CH}_{3}, \mathrm{Cl}, \mathrm{Br}, \mathrm{CN}, \mathrm{NO}_{2}$ on the electronic structure and properties, such as HOMO, LUMO, energy gap and dipole moment of 2,4-domino-5-p-substituted-phenyl-6-ethyl-pyrimidines by using the DFT method and B3LYP with 6-311G (d) basis set [9].

In the light of the above-mentioned, the aim of this work was to study the influence of hydrogen atom substitution by $\mathrm{NO}_{2}$ groups in different positions on the electronic and spectral properties for biphenyl and derivative molecules using the B3LYP functional and the $3-21 \mathrm{G}$ basis set.

\section{Calculations}

The DFT methods have been carried out using the Gaussian 09 program [10]. The geometric optimization of biphenyl $\mathbf{1}$ and derivative molecules 2-6 with the substitution of hydrogen atom by $\mathrm{NO}_{2}$ groups in the different positions have been performed with a B3LYP/3-21G level in the gas phase. The hybrid functional B3LYP basis set has been shown highly successful for calculating the electronic properties, such as electronic states, ionization potentials and energy gaps, since calculation of the exchange-correlation energy and interaction effects between electrons also show the most accurate results. Figure 1 shows the geometry optimization of biphenyl $\mathbf{1}$ and derivative molecules 2-6 in the gas phase using DFT methods with B3LYP/3-21G level. The EHOMO represents the energy of highest occupied molecular orbital, while ELUMO represents the lowest unoccupied molecular orbital.

The ionization potential $(I P)$ and electron affinity $(E A)$ in the framework of Koopmans' theorem could be calculated from the energies of $H O M O$ and $L U M O$ as follows by Eqs.(1) and (2) [11]:

$$
I P=-E H O M O
$$




$$
E A=-E L U M O
$$

The electronegativity $(\chi)$ has been calculated by Eq.(3) [12]:

$\chi=-\frac{I P+E A}{2}=-(E H O M O+E L U M O) / 2$

Where the hardness $(\eta)$ is defined by Eq.(4) [11]:

$$
\eta=\frac{I P-E A}{2}
$$

The softness $(S)$ and electrophilicity index $(W)$ have been calculated by using the Eqs. $(5)$ and $(6)[13,14]$ :

$S=\frac{1}{2 \eta}$

$W=\frac{\chi^{2}}{2 \eta}$

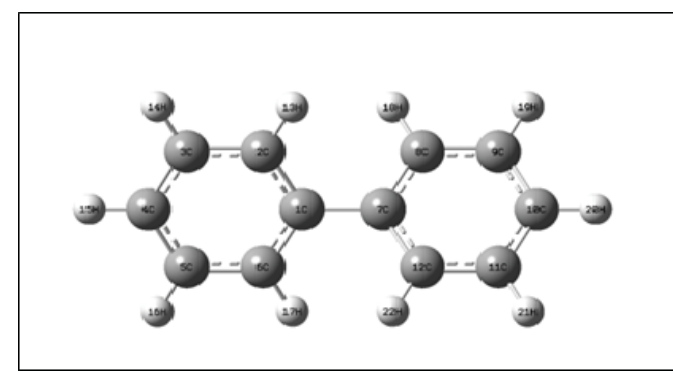

Biphenyl 1

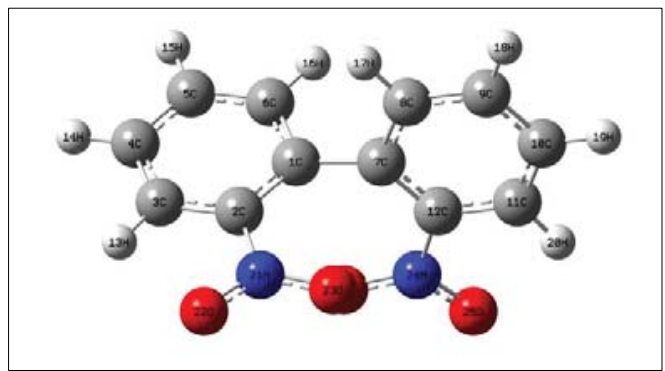

2,12-Dinitrobiphenyl 3

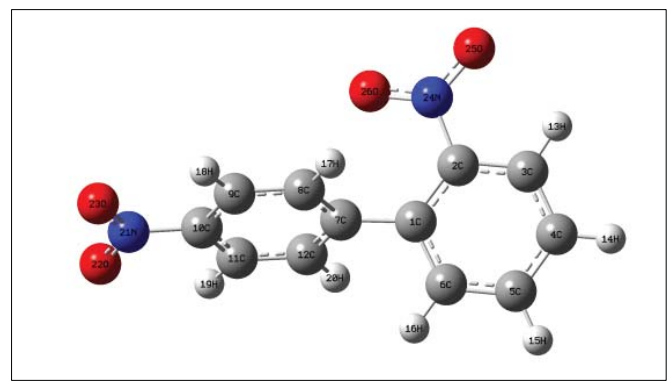

2,10-Dinitrobiphenyl 5

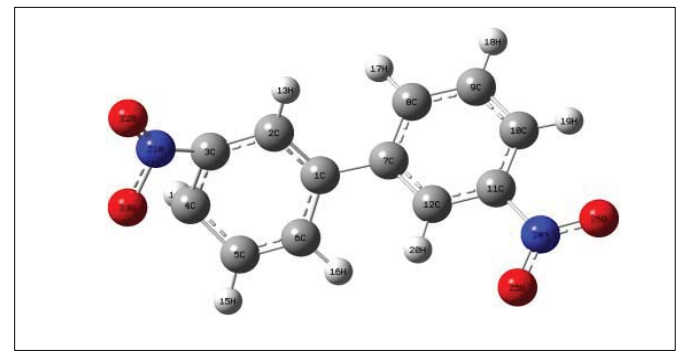

3,11-Dinitrobiphenyl 2

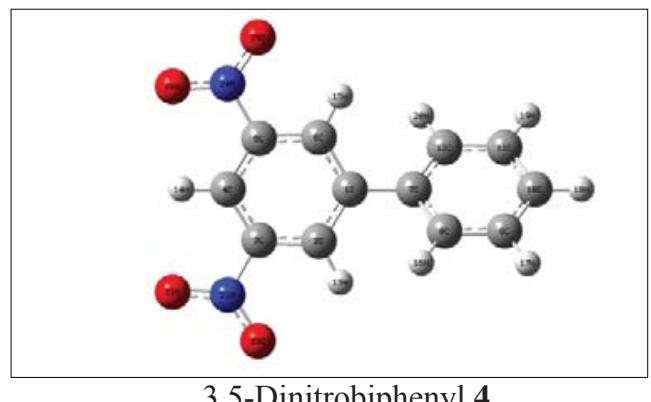

3,5-Dinitrobiphenyl 4

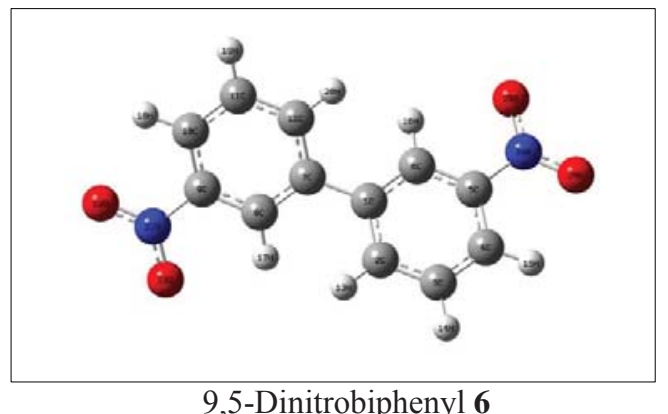

Figure 1. The optimized structures of biphenyl 1 and derivative molecules 2-6 using DFT-B3LYP/3-21G method.

\section{Results and discussion}

Molecular geometry

The optimized structural parameters of molecules calculated by using DFT -B3LYP levels with the 3-21G basis set are listed in Table 1, in accordance with the atom numbering scheme shown in Figure 1. As results from Table 1, there is no convergence between the bond lengths for $\mathrm{R}_{\mathrm{C}-\mathrm{C}}, \mathrm{R}_{\mathrm{C}-\mathrm{H}}, \mathrm{R}_{\mathrm{C}-\mathrm{N}}$ and $\mathrm{R}_{\mathrm{N}-\mathrm{O}}$ bonds. The $\mathrm{C}-\mathrm{H}$ bond lengths are in the 
range of $1.079-1.085 \AA$ and $\mathrm{C}-\mathrm{C}$ bond length is at $1.373 \AA$ and $1.498 \AA$, whereas $\mathrm{C}-\mathrm{N}$ bond length varies from $1.338 \AA$ to $1.476 \AA$. The N-O bond length of dinitrobiphenyl molecules varies in the range of $1.282-1.285 \AA$. All angles of the dinitrobiphenyl ring (C-C-C angles) vary from 117.602 to $120.220 \mathrm{~A}\left({ }^{\circ}\right)$.

\section{Electronic properties}

All properties are computed by the DFT/B3LYP 3-21G method for biphenyl 1 and derivative molecules 2-6. Table 2 shows the calculated energy values of $H O M O$ and $L U M O$ and electronic properties (values of $I P$ and $E A$ calculated by Eqs.(1) and (2), $\chi$ values (Eq.(3)), $\eta$ values (Eq.(4)), $S$ values (Eq.(5)), and $W$ values calculated by Eq.(6)). It is clear from Table 2 and Figures 2-7 that the substitution of hydrogen atom by $\mathrm{NO}_{2}$ group leads to decreasing the energy values of $H O M O$ and increasing the energy values of $L U M O$. Figures 2-7 show the electronic density distribution along the rings $\mathrm{C}$-C. In the different parts of dinitrobiphenyl molecules the electronic density distribution is homogeneous. It was noticed for all molecules that HOMO shows a bonding character and LUMO shows an antibonding character. While the values of $I P$ are increasing, the values of $E A$ are decreasing with the substitutions. The values of $\chi, \eta, S$ and $W$ are increasing. The approximate values of HOMO and $L U M O$ energies are in a good agreement with experimental values [15].

Optimized geometrical parameters of biphenyl 1 and derivative molecules 2-6,

Table 1 $\boldsymbol{R}(\AA)$ bond length, bond angles $A\left(^{\circ}\right)$.

\begin{tabular}{|c|c|c|c|c|}
\hline Molecules & Bond length & Our data $(\AA)$ & Bond angles & Our data $\left(^{\circ}\right)$ \\
\hline \multirow{5}{*}{ 1970 coves } & $\mathrm{R}(\mathrm{C} 1-\mathrm{C} 2)$ & 1.4051 & $\mathrm{~A}(\mathrm{C} 2-\mathrm{C} 3-\mathrm{C} 4)$ & 120.2203 \\
\hline & $\mathrm{R}(\mathrm{C} 1-\mathrm{C} 7)$ & 1.4886 & $\mathrm{~A}(\mathrm{C} 2-\mathrm{C} 1-\mathrm{C} 6)$ & 118.6205 \\
\hline & $\mathrm{R}(\mathrm{C} 2-\mathrm{C} 3)$ & 1.3949 & $\mathrm{~A}(\mathrm{C} 8-\mathrm{C} 7-\mathrm{C} 12)$ & 118.6205 \\
\hline & $\mathrm{R}(\mathrm{C} 3-\mathrm{C} 4)$ & 1.3970 & $\mathrm{~A}(\mathrm{C} 1-\mathrm{C} 6-\mathrm{H} 17)$ & 119.2746 \\
\hline & $\mathrm{R}(\mathrm{C} 2-\mathrm{H} 13)$ & 1.0840 & $\mathrm{~A}(\mathrm{C} 9-\mathrm{C} 10-\mathrm{C} 11)$ & 120.2203 \\
\hline \multirow{5}{*}{2} & $\mathrm{R}(\mathrm{C} 1-\mathrm{C} 2)$ & 1.3738 & $\mathrm{~A}(\mathrm{C} 2-\mathrm{C} 1-\mathrm{C} 6)$ & 119.5174 \\
\hline & $\mathrm{R}(\mathrm{C} 1-\mathrm{C} 7)$ & 1.4793 & $\mathrm{~A}(\mathrm{C} 4-\mathrm{C} 3-\mathrm{N} 21)$ & 94.8932 \\
\hline & $\mathrm{R}(\mathrm{C} 3-\mathrm{N} 21)$ & 1.3386 & $\mathrm{~A}(\mathrm{C} 1-\mathrm{C} 6-\mathrm{H} 16)$ & 116.6752 \\
\hline & $\mathrm{R}(\mathrm{C} 2-\mathrm{H} 13)$ & 1.0825 & $\mathrm{~A}(\mathrm{O} 25-\mathrm{N} 24-\mathrm{O} 26)$ & 125.7101 \\
\hline & $\mathrm{R}(\mathrm{N} 24-\mathrm{O} 26)$ & 1.2824 & $\mathrm{~A}(\mathrm{O} 22-\mathrm{N} 21-\mathrm{O} 23)$ & 125.8611 \\
\hline \multirow{5}{*}{3} & $\mathrm{R}(\mathrm{C} 1-\mathrm{C} 2)$ & 1.4012 & $\mathrm{~A}(\mathrm{C} 2-\mathrm{C} 1-\mathrm{C} 6)$ & 117.6027 \\
\hline & $\mathrm{R}(\mathrm{C} 1-\mathrm{C} 7)$ & 1.4984 & $\mathrm{~A}(\mathrm{C} 2-\mathrm{C} 3-\mathrm{N} 21)$ & 116.8991 \\
\hline & $\mathrm{R}(\mathrm{C} 2-\mathrm{N} 21)$ & 1.4613 & $\mathrm{~A}(\mathrm{C} 1-\mathrm{C} 6-\mathrm{H} 16)$ & 118.5167 \\
\hline & $\mathrm{R}(\mathrm{C} 3-\mathrm{H} 13)$ & 1.0794 & $\mathrm{~A}(\mathrm{O} 25-\mathrm{N} 24-\mathrm{O} 26)$ & 125.0666 \\
\hline & $\mathrm{R}(\mathrm{N} 24-\mathrm{O} 26)$ & 1.2850 & $\mathrm{~A}(\mathrm{C} 12-\mathrm{N} 24-\mathrm{O} 25)$ & 117.3061 \\
\hline \multirow{5}{*}{4} & $\mathrm{R}(\mathrm{C} 1-\mathrm{C} 2)$ & 1.4027 & $\mathrm{~A}(\mathrm{C} 2-\mathrm{C} 1-\mathrm{C} 6)$ & 118.3123 \\
\hline & $\mathrm{R}(\mathrm{C} 11-\mathrm{C} 10)$ & 1.3970 & $\mathrm{~A}(\mathrm{C} 2-\mathrm{C} 3-\mathrm{N} 21)$ & 118.9294 \\
\hline & $\mathrm{R}(\mathrm{C} 9-\mathrm{H} 17)$ & 1.0835 & $\mathrm{~A}(\mathrm{C} 1-\mathrm{C} 6-\mathrm{H} 15)$ & 121.7931 \\
\hline & $\mathrm{R}(\mathrm{C} 3-\mathrm{N} 21)$ & 1.4675 & $\mathrm{~A}(\mathrm{O} 25-\mathrm{N} 24-\mathrm{O} 26)$ & 126.1181 \\
\hline & $\mathrm{R}(\mathrm{N} 24-\mathrm{O} 26)$ & 1.2809 & $\mathrm{~A}(\mathrm{C} 3-\mathrm{N} 21-\mathrm{O} 23)$ & 116.9433 \\
\hline \multirow{5}{*}{5} & $\mathrm{R}(\mathrm{C} 1-\mathrm{C} 2)$ & 1.4030 & $\mathrm{~A}(\mathrm{C} 2-\mathrm{C} 1-\mathrm{C} 6)$ & 117.4296 \\
\hline & $\mathrm{R}(\mathrm{C} 11-\mathrm{C} 10)$ & 1.3886 & $\mathrm{~A}(\mathrm{C} 3-\mathrm{C} 2-\mathrm{N} 21)$ & 116.3391 \\
\hline & $\mathrm{R}(\mathrm{C} 9-\mathrm{H} 18)$ & 1.0797 & $\mathrm{~A}(\mathrm{C} 7-\mathrm{C} 12-\mathrm{H} 20)$ & 119.5894 \\
\hline & $\mathrm{R}(\mathrm{C} 10-\mathrm{N} 21)$ & 1.4625 & $\mathrm{~A}(\mathrm{~N} 22-\mathrm{O} 21-\mathrm{N} 23)$ & 125.6262 \\
\hline & $\mathrm{R}(\mathrm{N} 21-\mathrm{O} 22)$ & 1.2841 & $\mathrm{~A}(\mathrm{C} 10-\mathrm{N} 21-\mathrm{O} 23)$ & 117.1702 \\
\hline \multirow{5}{*}{6} & $\mathrm{R}(\mathrm{C} 1-\mathrm{C} 2)$ & 1.4069 & $\mathrm{~A}(\mathrm{C} 2-\mathrm{C} 1-\mathrm{C} 6)$ & 118.6886 \\
\hline & $\mathrm{R}(\mathrm{C} 10-\mathrm{C} 11)$ & 1.3928 & $\mathrm{~A}(\mathrm{C} 10-\mathrm{C} 9-\mathrm{N} 21)$ & 119.0676 \\
\hline & $\mathrm{R}(\mathrm{C} 10-\mathrm{N} 21)$ & 1.4667 & $\mathrm{~A}(\mathrm{C} 1-\mathrm{C} 2-\mathrm{H} 13)$ & 119.3218 \\
\hline & $\mathrm{R}(\mathrm{C} 2-\mathrm{H} 13)$ & 1.0834 & $\mathrm{~A}(\mathrm{O} 22-\mathrm{N} 21-\mathrm{O} 23)$ & 125.7443 \\
\hline & $\mathrm{R}(\mathrm{N} 21-\mathrm{O} 22)$ & 1.2824 & $\mathrm{~A}(\mathrm{C} 5-\mathrm{N} 24-\mathrm{O} 26)$ & 117.1239 \\
\hline
\end{tabular}

HOMO, LUMO energies and electronic properties (IP, EA, $\chi, \eta, S$ and $W)$ in (eV) units

Table 2 for biphenyl 1 and derivative molecules 2-6 using DFT with B3LYP/3-21G basis set.

\begin{tabular}{ccccccccc}
\hline Molecules & HOMO & LUMO & IP & $E A$ & $\chi$ & $\eta$ & $S$ & $W$ \\
\hline $\mathbf{1}$ & -6.21309 & -0.59891 & 6.213088 & 0.598914 & -3.40600 & 2.807087 & 1.403543 & 16.28228 \\
$\mathbf{2}$ & -6.02588 & -2.88681 & 6.025876 & 2.886815 & -4.45635 & 1.569530 & 0.784765 & 15.58466 \\
$\mathbf{3}$ & -7.14887 & -2.78532 & 7.148874 & 2.785318 & -4.96710 & 2.181778 & 1.090889 & 26.91446 \\
$\mathbf{4}$ & -7.19377 & -3.23566 & 7.193772 & 3.235660 & -5.21472 & 1.979056 & 0.989528 & 26.90850 \\
$\mathbf{5}$ & -7.27432 & -2.97416 & 7.274317 & 2.974162 & -5.12424 & 2.150077 & 1.075039 & 28.22818 \\
$\mathbf{6}$ & -7.34262 & -2.90450 & 7.342616 & 2.904502 & -5.12356 & 2.219057 & 1.109529 & 29.12608 \\
\hline
\end{tabular}




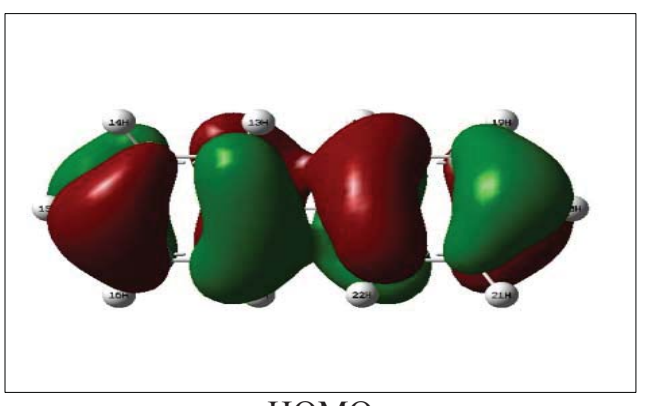

HOMO

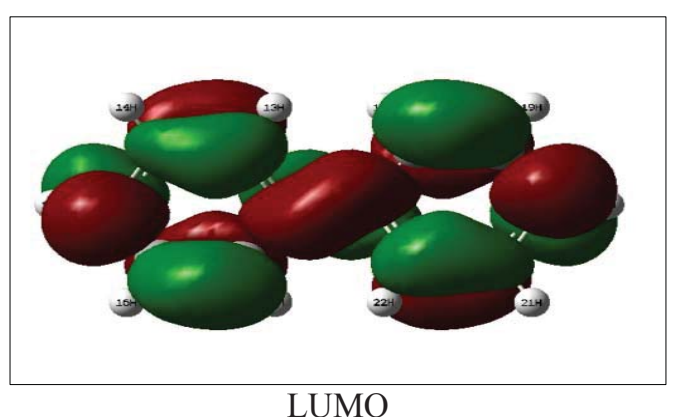

LUMO

Figure 2. HOMO and LUMO shapes of the biphenyl 1 molecule using the B3LYP/3-21G method.

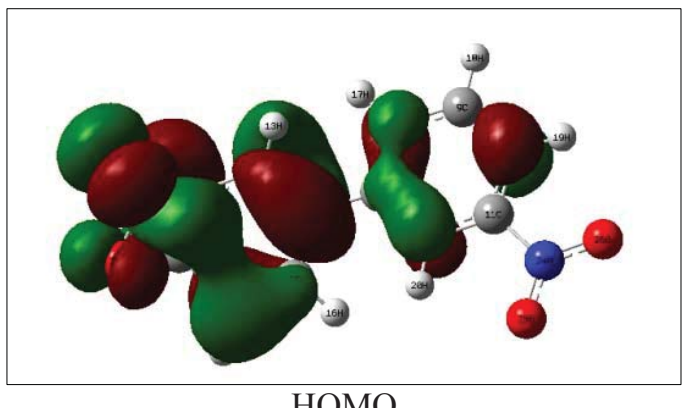

HOMO

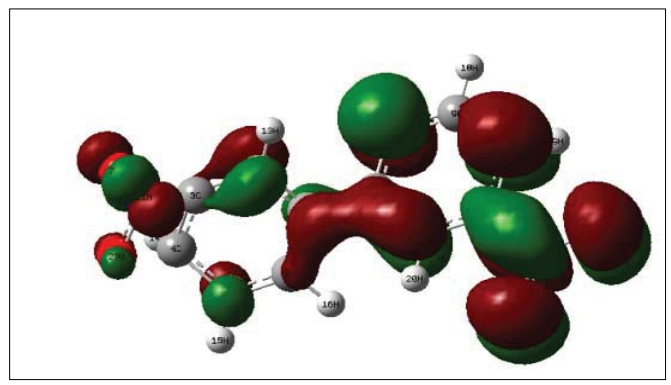

LUMO

Figure 3. HOMO and $L U M O$ shapes of the 3,11-dinitrobiphenyl 2 molecule using the B3LYP/3-21G method.

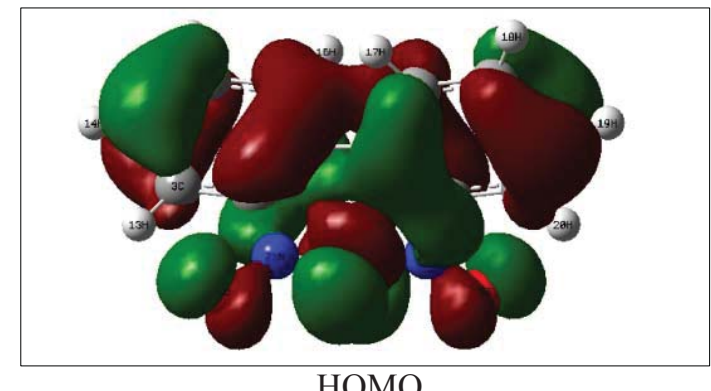

HOMO

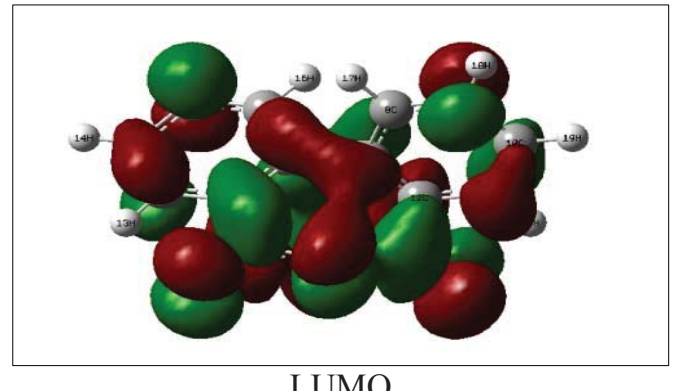

LUMO

Figure 4. HOMO and LUMO shapes of 2,12-dinitrobiphenyl 3 molecule using the B3LYP/3-21G method.

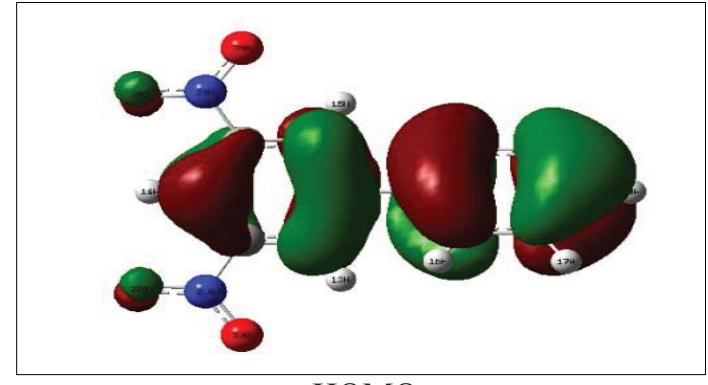

HOMO

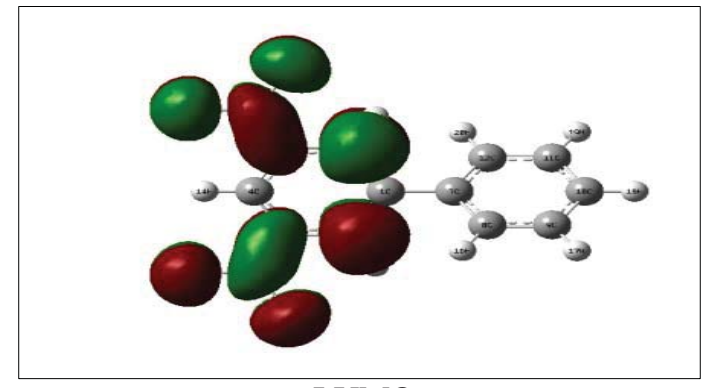

LUMO

Figure 5. $\mathrm{HOMO}$ and $L U M O$ shapes of 3,5-dinitrobiphenyl 4 molecule using the B3LYP/3-21G method. 

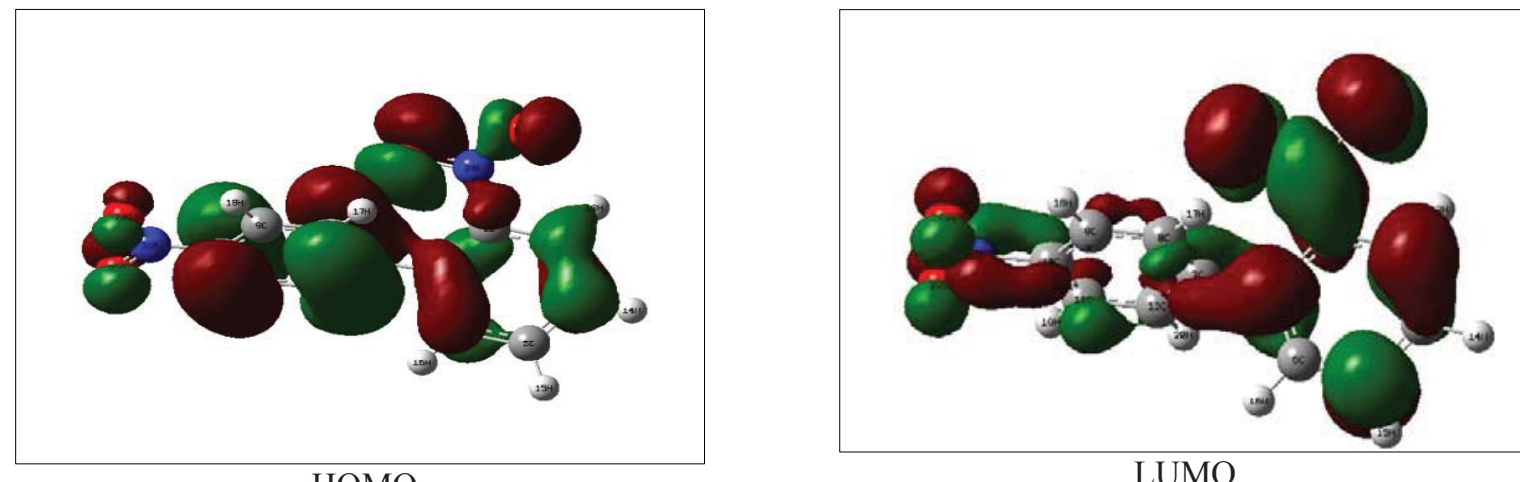

HOMO

LUMO

Figure 6. HOMO and $L U M O$ shapes of 2,10-dinitrobiphenyl 5 using the B3LYP/3-21G method.

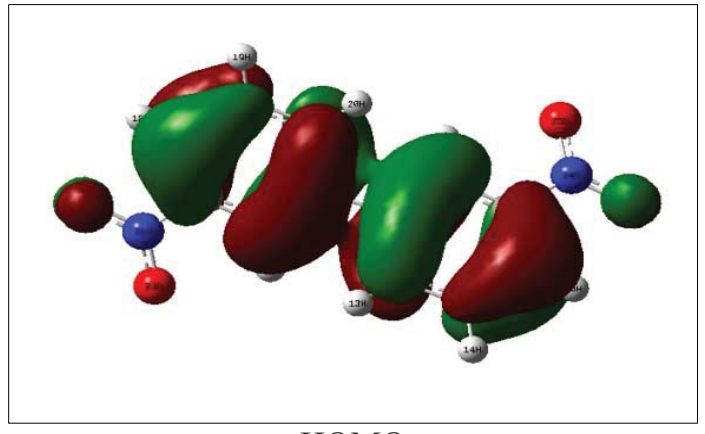

HOMO

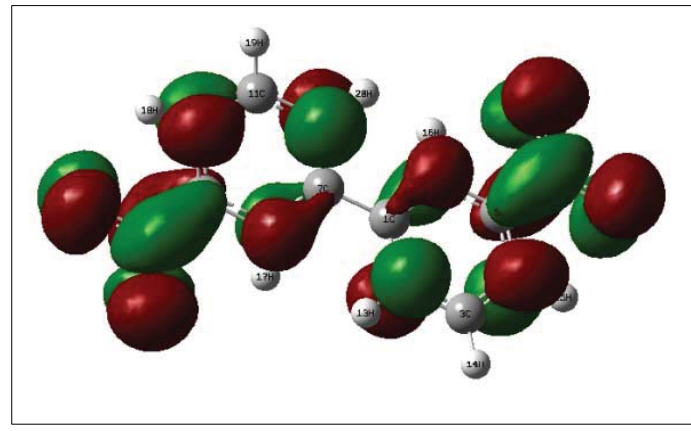

LUMO

Figure 7. HOMO and $L U M O$ shapes of 9,5-dinitrobiphenyl 6 molecule using the B3LYP/3-21G method.

\section{IR spectra}

Figures 8-10 show the computed IR spectra of biphenyl molecules 1-6. The harmonic vibrational frequencies were calculated for the studied molecules by using B3LYP level with a 3-21G basis set. The substitution of hydrogen atoms by $\mathrm{NO}_{2}$ leads to increasing in the number of vibrational modes. According to the rule of (3N-6), the biphenyl molecule has 60 degrees of freedom, while the dinitrobiphenyl molecules have 72 degrees of freedom. All degrees of freedom for biphenyl $\mathbf{1}$ and its derivatives 2-6 are represented by stretching, bending, rocking and scissoring mode. For a biphenyl molecule, the $(\mathrm{C}-\mathrm{H})$ symmetric stretching has been studied around $3221.33 \mathrm{~cm}^{-1}$ and asymmetric- at $3205.55 \mathrm{~cm}^{-1}$. The in-plane vibrations have been calculated at $957.55 \mathrm{~cm}^{-1}$. The out-of-plane $(\mathrm{C}-\mathrm{H})$ vibrations found at $557.30 \mathrm{~cm}^{-1}$ are in a good agreement with experimental values at $552.90 \mathrm{~cm}^{-1}[1]$. The (C-C) stretching vibrations have been studied in the region $1634.33 \mathrm{~cm}^{-1}$ and $(\mathrm{C}-\mathrm{C}-\mathrm{C})$ - at $516.16 \mathrm{~cm}^{-1}$. According to Figures $8-10$, in the IR spectra of dinitrobiphenyl molecules 2-6 the new peaks in the vibration modes are registered, in comparison with biphenyl molecule 1, due to existing of stretched bond, such as $(\mathrm{C}-\mathrm{N}),(\mathrm{C}-\mathrm{H})$ and $(\mathrm{N}-\mathrm{O})$ for 2-6 molecules. The symmetric stretching of (C-H) has been observed in the range of 3265.99-3225.80 $\mathrm{cm}^{-1}$ and asymmetric stretching- in the region $3194.29-3208.81 \mathrm{~cm}^{-1}$. The $(\mathrm{C}-\mathrm{N})$ stretching has been observed in the region $1600.77-1190.03 \mathrm{~cm}^{-1}$, whilst the stretching of (C-C) bond is shown in the range of $1648.56-1632.25 \mathrm{~cm}^{-1}$ and the stretching of $(\mathrm{N}-\mathrm{O})$ bond is shown in the region $1362.28-1458.81 \mathrm{~cm}^{-1}$. The $\mathrm{NO}_{2}$ groups have the rocking mode appeared in the region $74.03-270.29 \mathrm{~cm}^{-1}$, while the wagging modes appeared in the region $262.77-411.34 \mathrm{~cm}^{-1}$ and the scissoring mode appeared in the region $701.63-874.59 \mathrm{~cm}^{-1}$.
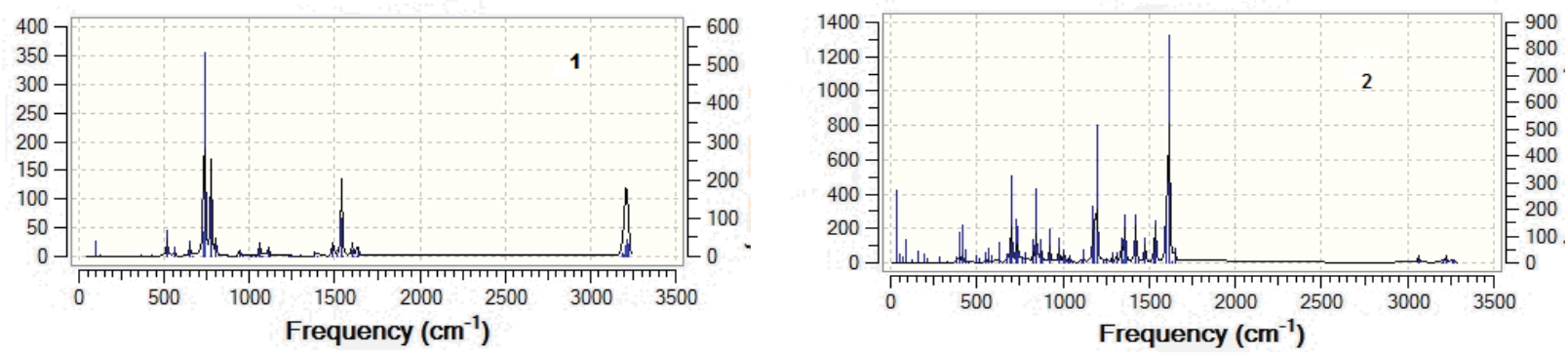

Figure 8. Calculated IR spectra of biphenyl 1 and its derivative 2. 

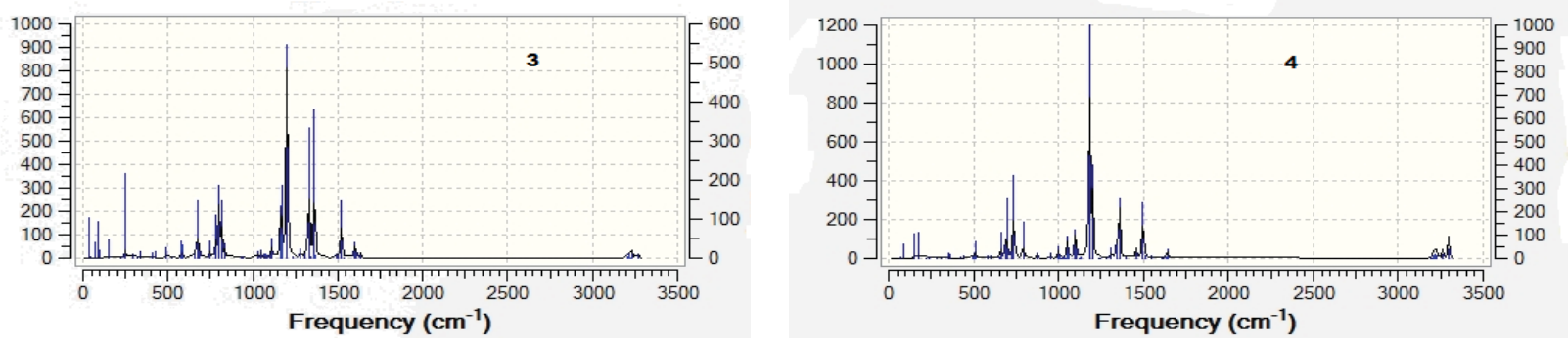

Figure 9. Calculated IR spectra of biphenyl derivatives 3 and 4.
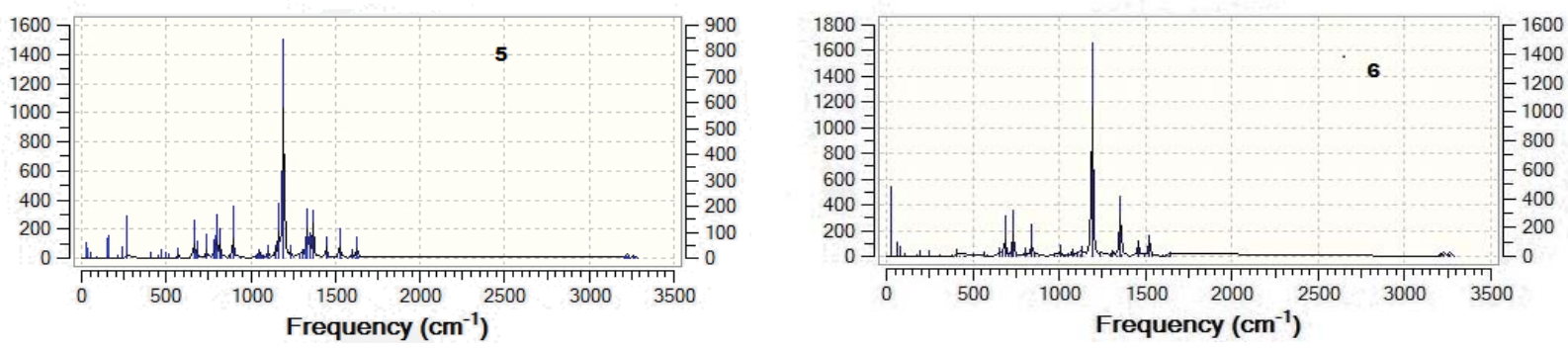

Figure 10. Calculated IR spectra of biphenyl derivatives 5 and 6.

\section{NMR spectra}

NMR spectra of ${ }^{1} \mathrm{H}$ and ${ }^{13} \mathrm{C}$ of biphenyl 1 and derivative molecules 2-6 (Figures 11-16) were computed by using the ChemBioDraw Program. Shielding has been considered to be one of the most effective factors that influence the chemical shift. In sites around the nucleus, where the electronic density is higher, the diamagnetic shielding becomes higher. It is clear from Figures 11-16 that the substitution of hydrogen atoms by $\mathrm{NO}_{2}$ groups in dinitrobiphenyl molecules 2-6 leads to increasing of the value of chemical shift in ${ }^{1} \mathrm{H}$ NMR spectra and weak increase in chemical shift of ${ }^{13} \mathrm{C}$ nuclei. The molecules $\mathbf{3}$ and $\mathbf{5}$ have a complex ${ }^{1} \mathrm{H}$ NMR spectrum, because of the mutual influences between the nuclei inside the molecules. The molecule 4 has high values of chemical shift for ${ }^{1} \mathrm{H}$ nuclei that are found in the interval 7.4 $9.4 \mathrm{ppm}$ and ${ }^{13} \mathrm{C}$ nuclei in the interval $117.0-149.3 \mathrm{ppm}$. This is due to the effect of electronic density cyclic currents and electrons delocalization causing the strong shielding. The values of chemical shifts for ${ }^{1} \mathrm{H}$ and ${ }^{13} \mathrm{C}$ nuclei in NMR spectra for biphenyl $\mathbf{1}$ are in a good agreement with experimental values [16].
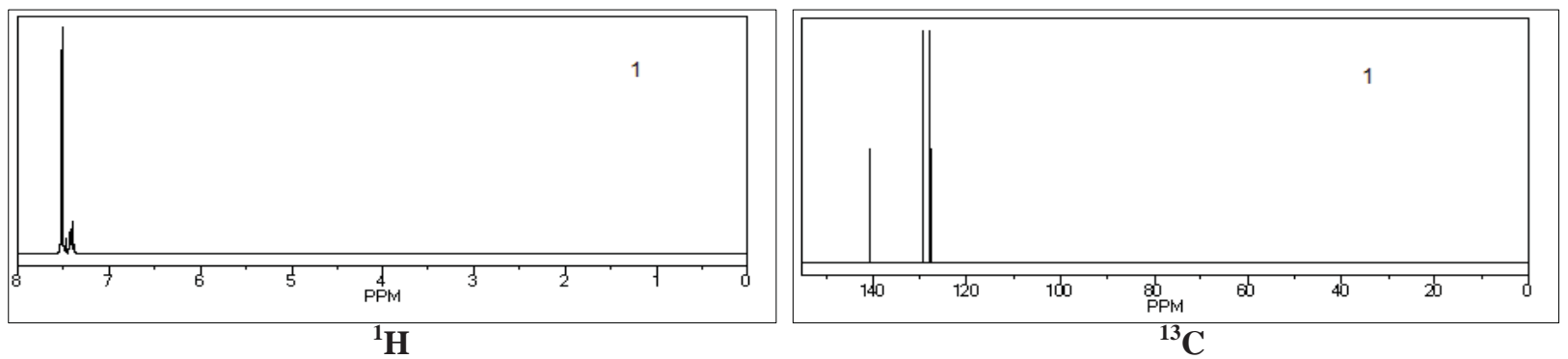

Figure 11. Predicted ${ }^{1} \mathrm{H}$ and ${ }^{13} \mathrm{C}$ NMR spectra for biphenyl 1.

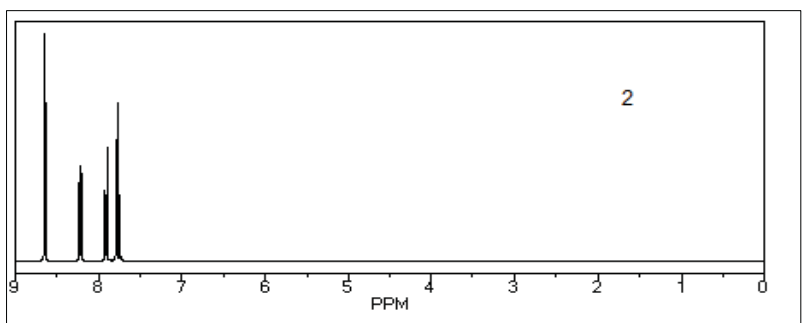

${ }^{1} \mathbf{H}$

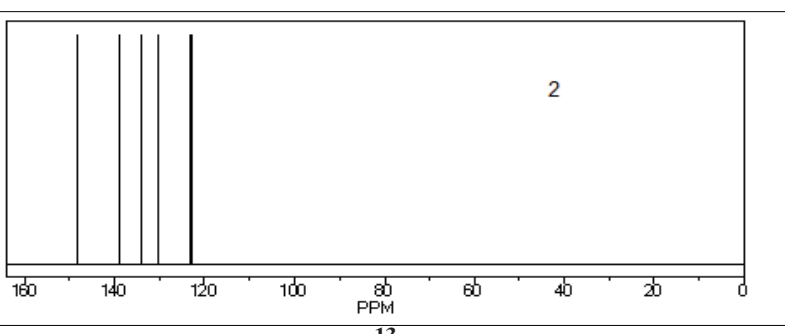

${ }^{13} \mathrm{C}$

Figure 12. Predicted ${ }^{1} \mathrm{H}$ and ${ }^{13} \mathrm{C}$ NMR spectra for biphenyl derivative 2. 

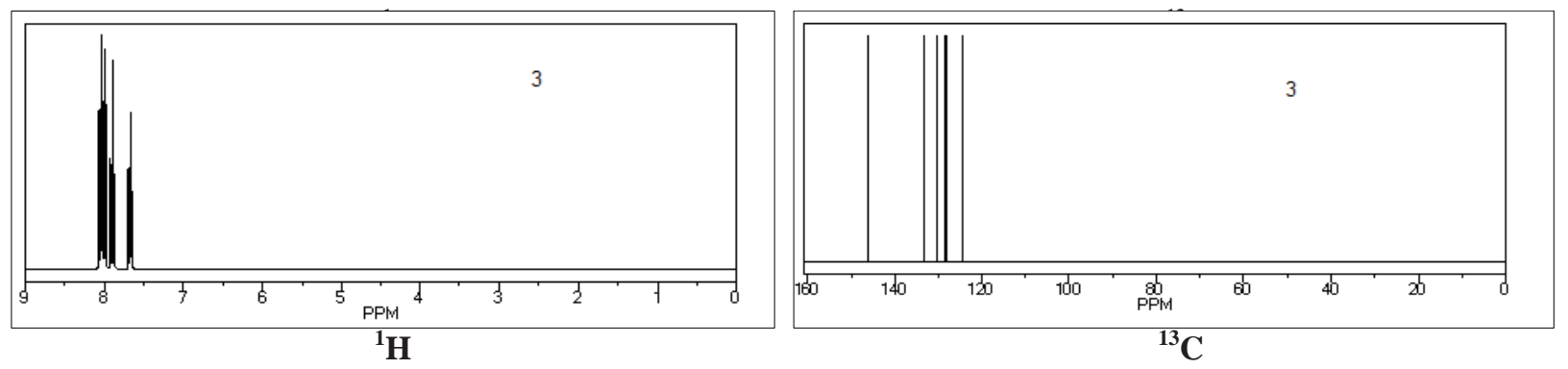

Figure 13. Predicted ${ }^{1} \mathrm{H}$ and ${ }^{13} \mathrm{C}$ NMR spectra for biphenyl derivative 3.
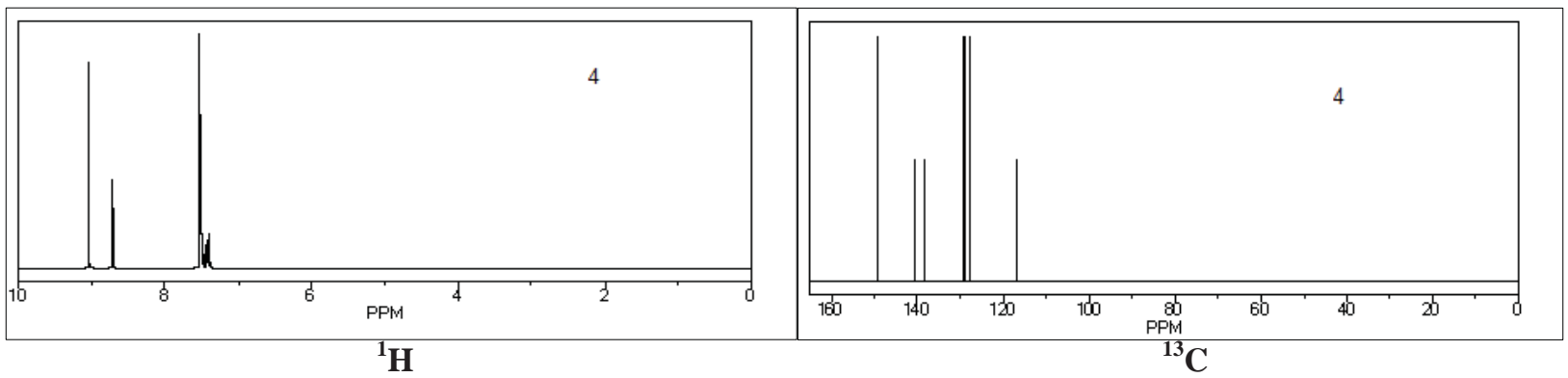

Figure 14. Predicted ${ }^{1} \mathrm{H}$ and ${ }^{13} \mathrm{C}$ NMR spectra for biphenyl derivative 4.
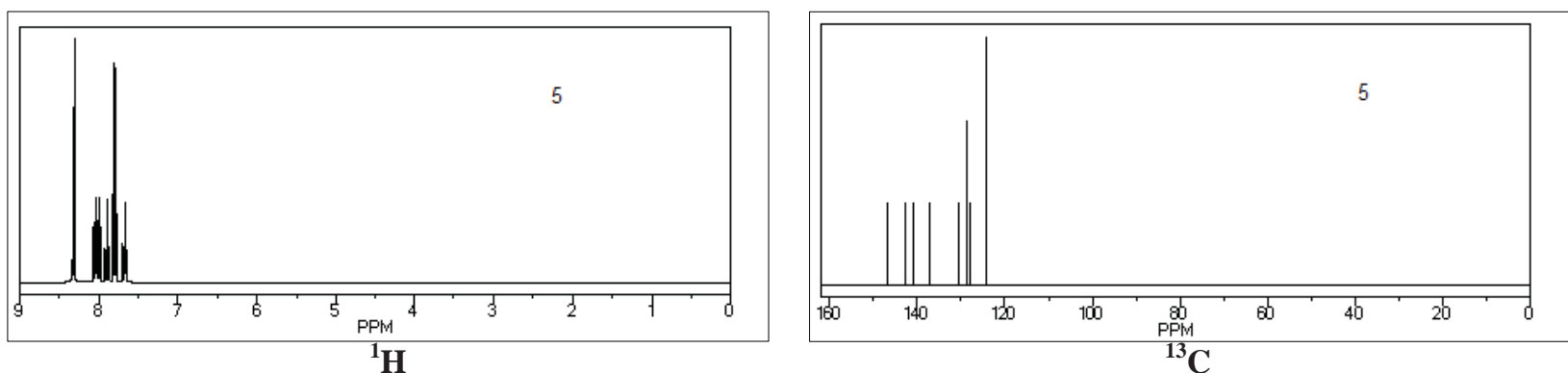

Figure 15. Predicted ${ }^{1} \mathrm{H}$ and ${ }^{13} \mathrm{C}$ NMR spectra for biphenyl derivative 5.
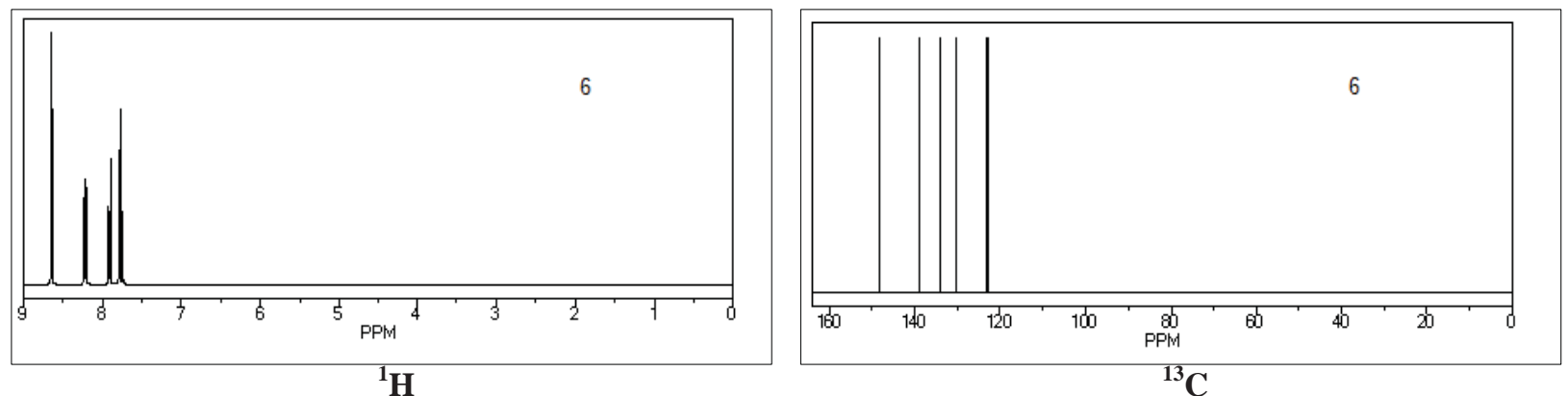

Figure 16. Predicted ${ }^{1} \mathrm{H}$ and ${ }^{13} \mathrm{C}$ NMR spectra for biphenyl derivative 6.

\section{Conclusions}

The values of geometric optimization (bond length and its angles) for dinitrobiphenyl molecules 2-6 are slightly different in the case of substitution of hydrogen by $\mathrm{NO}_{2}$ groups, also depending on the substituted atom's position.

The HOMO energy values are decreasing, while the LUMO energy values are increasing at the substitution of hydrogen atoms by $\mathrm{NO}_{2}$ groups, the HOMO and $L U M O$ energy values for biphenyl molecule $\mathbf{1}$ being in a good agreement 
with experimental values. The electronic density is distributed to the different parts of dinitrobiphenyl molecules 2-6 and along the $\mathrm{C}-\mathrm{C}$ rings.

The values of $I P$ are increasing, while the values of the $E A$ are decreasing in case of the substitution of the hydrogen atoms by $\mathrm{NO}_{2}$ groups, while the calculated values of $\chi, S, \eta$ and $W$ are increasing.

According to the IR spectra, the substitution of hydrogen atoms by $\mathrm{NO}_{2}$ groups leads to increasing the number of vibrational modes, also the stretching vibrations of dinitrobiphenyl molecules 2-6 are increasing compeer with biphenyl molecule $\mathbf{1}$.

According to the data of ${ }^{1} \mathrm{H}$ and ${ }^{13} \mathrm{C}$ NMR spectra, it was found that the substitution of hydrogen atoms by $\mathrm{NO}_{2}$ groups causes appearance of new peaks for dinitrobiphenyl molecules 2-6. The molecules $\mathbf{3}$ and $\mathbf{5}$ have a complex ${ }^{1} \mathrm{H}$ NMR spectrum, because of the mutual influences between the nuclei inside the molecules, which lead to increase in intensity of some lines with respect to the other spectrum lines. The molecule $\mathbf{4}$ has high values in chemical shift of ${ }^{1} \mathrm{H}$ nuclei and ${ }^{13} \mathrm{C}$ nuclei in comparison with the other dinitrobiphenyl molecules.

\section{Acknowledgments}

I gratefully thank to my supervisor Prof. Dr. Dhia Hamdi Al-Amiedy, College of Science for Women, University of Baghdad-Iraq, for his invaluable assistance during preparation of this paper.

\section{References}

1. Zhuravlev, K.K.; McCluskey, M.D. Infrared spectroscopy of biphenyl under hydrostatic pressure. Journal of Chemical Physics, 2002, 117(8), pp. 3748-3752.

2. Budavari, S.; O’Neil, M.J.; Smith, A.; Heckelman P.E. Eds. The Merck Index. $11^{\text {th }}$ Edition, Merck\&Co Inc.: New York, 1989, $1258 \mathrm{p}$.

3. Sittig, M. Ed. Handbook of Toxic and Hazardous Chemicals and Carcinogens. $2^{\text {nd }}$ Edition, Noyes Publications: New York, 1985, 3040 p.

4. Robertson, W.; Hansen, G. PCBs: recent advances in environmental toxicology and health effects. University Press of Kentucky, Lexington, KY: Kentucky, 2001, p. 11

5. O’Neil, M. The Merck Index, 14 ${ }^{\text {th }}$ Edition, Merck\&Co Inc.: New York, 2006, p. 204.

6. Chen, F.-F.; Wang, F. Electronic structure of the azide group in 3'-azido-3'-deoxythymidine (AZT) compared to small azide compounds. Molecules, 2009, 14(7), pp. 2656-2668.

7. Kumar Pandey, A.; Bajpai, A.; Baboo, V.; Dwivedi, A. Structural, electronic, and vibrational properties of isoniazid and its derivative N-cyclopentylidenepyridine-4-carbohydrazide: A quantum chemical study. Journal of Theoretical Chemistry, 2014, Article ID 894175, 15 p., doi:10.1155/2014/894175.

8. Glossman-Mitnik, D.; Barraza-Jiménez, D.; Flores-Hidalgo, M.A.; Rodriguez-Valdez, L.M. Molecular structure and substitution effects on diphenylanthrazolines for organic semiconductors: A theoretical study. Journal of Molecular Structure, 2008, 863, pp. 99-104.

9. Saleha, B.A.; Abood, H.A.; Miyamoto, R.; Bortoluzzi, M. Theoretical study of substituent effects on electronic and structural properties of 2,4-diamino-5-para-substituted-phenyl-6-ethyl-pyrimidines. Journal the Iranian Chemical Society, 2011, 8(3), pp. 653-661.

10. Frisch, M.J.; Trucks, G.W.; Schlegel, H.B. et al. Gaussian 09, Revision A.02; Gaussian, Inc.: Wallingford, CT, 2009.

11. Vektariene, A.; Vektaris, G.; Svoboda, J. A theoretical approach to the nucleophilic behavior of benzofused thieno[3,2-b]furans using DFT and HF based reactivity descriptors. ARKIVOC, 2009, (vii), pp. 311-329.

12. Dwivedi, A.; Baboo, V.; Bajpai, A. Fukui function analysis and optical, electronic, and vibrational properties of tetrahydrofuran and its derivatives: a complete quantum chemical study. Journal of Theoretical Chemistry, 2015, Article ID 345234, 11 p., doi:10.1155/2015/345234.

13. Zeroual, A.; Hammal, R.; Ryachi, K.; Barhoumi, A.; Benharref, A.; Hajbi, A.El. Understanding the regioselectivity and reactivity of $\beta$-himachalene using zeroual function as a new regioselectivity. International Journal of Innovation and Applied Studies, 2014, 8(2), pp. 750-755.

14. Parr, R.; von Szentpa'ly, L.; Liu, S. Electrophilicity index. Journal of the American Chemical Society, 1999, 121, pp. 1922-1924.

15. von Marius, B. Phase coherent electronic transport through single molecules and graphene nanostructures. Universität Karlsruhe (TH), 2008. http://www.tfp.uni-karlsruhe.de/Publications/Pub2008/diplom_buerkle.pdf.

16. Jin, Y.; Lei, W. Synthesis and Characterization of Dinuclear NHC-Palladium Complexes and Their Applications in the Hiyama Reactions of Aryltrialkyoxysilanes with ArylChlorides. Electronic Supplementary Material (ESI) for Dalton Transactions, 2012. http://www.rsc.org/suppdata/dt/c2/c2dt31174g/c2dt31174g.pdf. 